\title{
Astronomy Research Seminar - The Impact on Students from their Perspective. Preliminary results from one spring seminar.
}

\author{
Rachel Freed ${ }^{1,2 *}$
}

\begin{abstract}
In an effort to give undergraduate and high school students an experience of the processes of scientific research as close to what they might expect in the field, the Astronomy Research Seminar has been taught out of Cuesta Community College in San Luis Obispo, CA, for over a decade, and for the past 3 years as a distance education course. The hope is that in providing early exposure to scientific research in a way that as closely as possible resembles the scientific endeavor outside of the classroom, more students will be given the tools to continue to pursue science in their education and careers, specifically the perseverance in the challenge of writing a scientific paper for publication. Here we present an analysis of an initial evaluation of the seminar by looking at students' self-reported feelings about how the seminar has inspired them, and helped them learn to manage projects, write scientific papers and take charge of their own learning.

${ }^{1}$ Sonoma State University, Sonoma, CA, USA

${ }^{2}$ Institute for Student Astronomical Research (InStAR)

*Corresponding author: r.freed2010@gmail.com
\end{abstract}

\section{Introduction}

True student research in astronomy has been slowly developing over the last few decades (Fitzgerald et al., 2014) with the continuing increase in sophistication and availability of technology to the education and amateur community. As noted in a recent review (Gomez and Fitzgerald, 2017), the educational outcomes have not matched in quality or quantity of the technical outcomes of this technology. In this paper I explore some preliminary results from students involved in an approach which attempts to breach this gap, a semester long astronomy research seminar first trialled by Russ Genet (Genet et al., 2010) which has expanded to other areas (Genet et al., 2017) and resulted in many student research publications (Freed et al., 2017)

The astronomy research seminar is a program in which, within the course of a semester or less, students learn some content about double stars and astrometry (Genet et al., 2012), come up with a research project, go through the process of collecting data, analyze their data to find the position angle and separation of a pair of binary stars and then write up their results. The results are written up in a paper they submit for publication to the Journal of Double Star Observations (Clark, 2010). They go through numerous rounds of revisions on the paper, and have it externally peer-reviewed as many times as necessary to make it publication worthy, until it is accepted for publication. They also give presentations on their project at the end of the semester. Over the past 12 years, numerous students have presented at conferences such as the Annual Conference of the Society for Astronomical Sciences (e.g. Johnson 2008) and various International Double Star Conferences. 


\section{Astronomy Research Seminar - The Impact on Students from their Perspective. Preliminary results from one spring seminar. -288}

The theoretical framework which may underlie the perceived successes of this program over more than a decade is the immersion of students and their teams within a Community-of-Practice (Wenger, 1999). The seminar is currently undergoing evaluation to determine both the short term and long term impacts on student education and career choices looking to see if participation in anyway influences students to follow a path in science. In this paper we present some initial findings from student reflections on the value of the course for them in their educational and career settings and trajectories.

\section{History of the astronomy research seminar}

The Astronomy Research Seminar was originally taught as an in-person course at Cuesta Community College by Dr. Russell Genet beginning in 2006 (Genet, 2007). The course has been taught there continuously most semesters in the intervening 11 years in addition to being taught at Concordia University over several summers and at the University of Hawaii during several winters. In 2013, an online version of the course was created and 10 high schools from around the country had teams of students and their teachers take the course through Cuesta Community College's Distance Education Program.

The seminar has since expanded to the San Diego, California area, with three new Community Colleges offering the course. Between 2006 and 2017 almost 200 student research papers have been published, including over 400 student co-authors (Freed et al., 2017). The Research Seminar is now expanding rapidly, in both geographical distribution and the types of projects students will be able to do, including but not limited to Exoplanet Transits and Asteroid Rotation Light Curves.

This seminar is unique in the fact that it requires publication by students within the course of the semester. This requirement has meant that so far the options for student research projects have been limited to topics that can definitely be covered within such a short period of time, such as double star astrometry. The students select a project, write a proposal, collect and analyze data, and write their paper and submit it for publication. The new data points that the students have collected are eventually added to the Washington Double Star Catalog maintained by the US Naval Observatory ${ }^{1}$.

\section{Format of the Astronomy Research Seminar Course}

Over the past several years numerous different versions of the Research Seminar have been developed at a range of institutions, from middle schools, high schools, community colleges, the Institute for Student Astronomical Research, and other organizations. The general format of the courses is similar. Students learn about astronomical research as well as some basic content knowledge about double stars, exoplanet transits, or asteroids, depending on the seminar topic, from instructors and videos that have been created for the course. They are guided through the process of selecting a target of study. For example, the instructor might show them how 10-15 double star targets were selected from a database of 4000 , by selecting for certain magnitudes, separations and delta magnitudes that could be observed by the telescopes being used for the project. Then the student teams could select which of those targets they would like to study and be guided through the process of submitting an image request on a telescope or network (Skynet, Las Cumbres Observatory, an advanced amateur's personal observatory, etc...), and then learn through tutorials and in weekly meetings how to make astrometric measurements on their images. In the meantime, they have written a proposal for their project, which may have undergone revision based on the instructor's or other external reviewer's suggestions, and then they begin writing their paper. There is a textbook and a learning management system for the course, which helps guide students through these processes. They are also expected to meet on their own and in short order take on

\footnotetext{
${ }^{1}$ http://ad.usno.navy.mil/wds/
} 


\section{Astronomy Research Seminar - The Impact on Students from their Perspective. Preliminary \\ results from one spring seminar. -289}

leadership roles for their team, as a focus of the seminar is learning how to work as a collaborative and independent team to the extent possible.

As the students are required to write and actually publish a paper, a significant amount of the course time is dedicated to teaching students how to write a scientific journal article. They learn to go through the process of selecting their target, writing and presenting a proposal, and collecting and analyzing the data all within the first half of the course, while the second half of the course is mostly devoted to writing up a draft of their paper and being guided through the process of rewriting and refining their paper numerous times. After significant improvements have been made on the draft based on working with the instructor, the students are connected with external reviewers who are familiar with the field and they send them the paper asking for feedback which is then incorporated. The final step after many iterations is to send the paper off to a journal, most often the Journal of Double Star Observations, for publication. It is then reviewed again and generally sent back for more revisions before eventually being accepted.

The students also learn the value of interacting with members of the community external to their course, such as experts in the field who may be professional scientists or advanced amateur astronomers, or software developers who have written programs for image analysis, who can review their paper, advise them on their analysis and critique their scientific processes. One of the big lessons students are presented with in the course is that science is messy, that it doesn't conform to the neat and tidy scientific method that they are taught in school, that the data collected isn't always straightforward and doesn't always fit a pattern or give direct answers. They also discover that the expert's don't have all of the answers either. A major goal of the astronomy research seminar is to teach students, through experience, what scientific research is like in the real world.

\section{Current Sample}

In the spring of 2017, a class of students in the Astronomy Research Seminar was surveyed on their own reflections about the value of the course. The survey, shown in Appendix A, was anonymous in the hopes this would allow for more honest feedback. They were asked, in an open-ended fashion, how they felt about all the writing, about the value of working in teams, and how they felt this might impact their future educational and career goals. They were also asked about the value of the course materials and the learning management system (LMS) as part of an ongoing effort to improve the seminar. The students in these classes had been originally recruited from advanced math and engineering courses at Cuesta College. It's important to note, however, that over the years the seminar often contains large numbers of students who are not already on a STEM-path.

Of the 40 students in the Spring Research Seminar, 22 responded to the survey. $91 \%$ of the respondents were college students while $9 \%$ were high school students. Of all the respondents $55 \%$ stated they were interested in becoming engineers, $18 \%$ scientists, $9 \%$ computer scientists and the remaining $18 \%$ listed a variety of non-science-related careers or stated that they didn't know yet what they wanted to pursue. The survey questions can be broadly grouped into a few categories including questions about "the benefits of the seminar", "inspiration from the course", "writing in science", "autonomy as a team", "learning about the research process" and "course structure and support".

\section{Results}

\section{Benefits of the seminar}

A concern that has often been brought up by instructors about the Astronomy Research Seminar is that a significant portion of the seminar is dedicated to writing, and re-writing the paper. If students weren't fully aware that the course involves more writing than learning about astronomy content it was hypothesized that this could frustrate them and drive them away from the 


\section{Astronomy Research Seminar - The Impact on Students from their Perspective. Preliminary results from one spring seminar. -290}

course. New seminar instructors have commented "My students are really going to want to learn astronomy. That's why they are taking this course". This concern, combined with the fact that most of the students in the Spring course were recruited from advanced math and engineering courses, made the survey results regarding writing unexpected.

In response to the question "How did the Astronomy Research Seminar Most Benefit You?", 10 out of the 22 participants $(45 \%)$ stated that learning to write a scientific paper was the greatest or one of the greatest benefits. Of these 10, three also listed learning to do research as one of the greatest benefits.

"It was an excellent introduction to academic research and writing."

- Student 1

"I learned the basics of writing a research paper"

- Student 2

"I learned how to write a research paper, and how to work as a team in a real world way (unlike the "equal participation" stuff I have learned to dislike). I wasn't really in it for the astronomy, but it turns out that was pretty fun too."

- Student 3

$36 \%$ percent of the students ( 8 out of 22 ) said that learning about the research process, or the true scientific method was what most benefited them. $23 \%$ referenced learning the value of working in teams as very beneficial for them. Interestingly, only 3 students (14\%) mentioned anything about astronomy content as one of the biggest benefits and only 1 student mentioned the fact they they would have a published paper in their portfolio as a benefit. The latter student, in response to the question "Did the Seminar Inspire You in any Way?" stated "Yes, I liked the process of creating a research paper and I want to do it more in the future", indicating that they were not in it just to have a published paper for their CV.

\section{Student Inspiration}

The students were asked "Did the seminar inspire you in any way?". 8 of the 22 participants (36\%) directly stated that it inspired them to pursue or continue pursuing research in the future.

"Yes, it introduced me to the field of scientific research which I will most likely continue to be a part of in the future"

- Student 4

"The seminar inspires me to appreciate scientific research more and to incorporate something like this in my future. I would like to write more scientific papers."

- Student 5

"Yes. It inspired me to take astronomy classes and learn more about astronomy and to conduct more research in the future."

- Student 6

Four students (18\%) stated that the seminar inspired them to learn astronomy or continue pursuing astronomy in their education. One student wrote "It gave me the taste of astronomy that I wanted, since I previously thought about majoring in astronomy, and it made me feel that astronomy research is a real thing that I can do even as a hobby for the rest of my life."

Of the 22 responses to this question, $82 \%$ claimed to be positively inspired. Four students were not and in response to the question "Did the seminar inspire you" they wrote "No", "Not particularly", "No, because I'm already in a STEM major" and "Not a whole lot. I went into the class knowing nothing about astronomy which left me overwhelmed." This last response is important because a unique feature of the Astronomy Research Seminar is that there are no prerequisites, specifically to keep the program open and accessible to as many students as possible, including those who may not normally be inclined to take science and math classes. 


\section{Astronomy Research Seminar - The Impact on Students from their Perspective. Preliminary results from one spring seminar. -291}

\section{Writing in Science}

The most unique aspect of the astronomy research seminar is its requirement for publication of research results. This is a crucial part of the scientific endeavor, contributing results to the community. The survey included the question "When you realized how much careful writing scientists have to do, did this discourage you from thinking about becoming a scientist?" and surprisingly, 20 of the 22 participants $(91 \%)$ were not discouraged by the amount of writing.

"No, it's good to be precise."

- Student 7

"Since I'll be involved in medical research it definitely did not discourage me. It just showed me that I have a long way to go."

- Student 8

"No, actually the opposite. Creative writing and narratives can be challenging, but I found scientific research to be enjoyable and pleasant because there was a very clear format to follow. After that, editing in stages was simple."

- Student 9

"No, it makes the profession more approachable to me.".

- Student 10

The two students who said they were discouraged actually stated they had never planned on becoming a scientist, but the writing would have discouraged them had they been so inclined. The students were asked how difficult it was for them to write the paper. Thirty five percent responded that it was easy, $61 \%$ that it was moderately difficult, and $4 \%$ that it was very difficult.

\section{Autonomy as a Team}

A major goal of the astronomy research seminar is to simulate as much as possible what the real research experience is like and this involves giving student teams as much autonomy as possible given their novice status in both research experience and the study of astronomy. Students work in teams that are encouraged to meet externally to the required course meetings and are explicitly guided through the process of making their own decisions when possible. Several of the survey questions were aimed at looking at the perceived success or lack thereof of this aspect of the seminar.

"Do you feel your team managed its own research or did the research supervisor actually run the show for you?" This was a multiple choice question with the following options "The team managed its own research, with some help from the supervisor.", "The supervisor mainly managed the research." and "other". $96 \%$ of the students (22/23) indicated that the team managed its own research. One student selected "other" and commented as shown below.

"Both. We could not have done this without SRO [Sierra Remote Observatories] [and the instructors]. Still, my team was very involved in the project"

- Student 11

Another question getting to the heart of the "real research experience" asked "Did you feel that you were able to make real choices, or was the path pretty well set in stone? Please briefly explain." $41 \%$ of the students stated that they felt they were able to make real choices about their research

I think we were able to make real choices, we had to come up with most of the project on our own, the professors didn't hold our hands but were there to guide and help us when we needed assistance and guidance.

- Student 12

and $36 \%$ stated that they felt like the research project was "set in stone" without the opportunity to make real choices.

I did not feel that we had many choices to make, but I'm not sure how 


\section{Astronomy Research Seminar - The Impact on Students from their Perspective. Preliminary results from one spring seminar. -292}

that could change. Perhaps a greater set of choices - or at least more time to make a choice - in choosing our star could help.

- Student 13

The other $23 \%$ felt it was somewhere in between, that they had some things they could choose, but some aspects of the research were already determined.

We had a guided path that I appreciated. But we had the responsibility of forming our own thesis. So, both are true.

- Student 14

In keeping with the goal of giving students the actual experience of doing science, from the proposal writing stage to publication of their results, there is significant emphases on the importance of teamwork and the idea that, unlike in a traditional classroom, team members will contribute unequally in terms of their time and their actual contributions to the process. This is how real science works, with different team members contributing what they can based on their specific skill sets and the availability of their time, at least to some extent. These are new ideas to students who are generally taught that every team member should contribute equally. Some students ended up appreciating this new approach, although certainly not all of them. The survey asked "Did your team members contribute equally to the team's project. If not, did this bother you that they didn't contribute equally? Did your team adjust author order in the final paper to take into account the degree of individual participation? Do you think what you came up with was fair?".

"I felt like I put in the most work from the group. This didn't bother me, because I was first author. The system seemed very fair."

- Student 15

"All of the team members did not contribute equally; it did bother me some as I ended up doing most of the work. We did adjust the author order, but in the end it still did not seem quite fair."

- Student 16

It is hoped that the seminar, in giving students a feel for scientific research, will then make them feel that they can contribute to research in the future. They were asked in the survey, "Did your contribution to your team's research make you feel like you could contribute to teams in the future?" $77 \%$ of the respondents said "yes" and $13 \%$ equivocally stated "perhaps".

"Yes. I found it easy to make a significant contribution and be somewhat of a team leader. I believe I could do this well again."

- Student 17

\section{Science content in the context of a research seminar}

While the emphasis of the seminar is not on actual astronomy content, it is assumed that in the process of doing the research, analyzing data and preparing a paper for publication students will learn the content relevant to their area of research. The questionnaire addressed content learning from the students perspective with the following multiple choice question: "By the end of the seminar did you have at least a rough feel for what double star astrometry was about or did it remain confusing to the very end?" $61 \%$ of the students selected the option "I understand pretty well what double star astrometry is. I could explain it to someone else." while $35 \%$ of the students selected "I understand a little bit about what double star astrometry is." and 4\% (1 student) selected "I am still unsure what double star astrometry is." A further place to assess student learning outcomes is in the presentations that students are required to give at the end of the seminar.

\section{Discussion}

The Astronomy Research Seminar is unique in several ways including the percentage of time in 


\section{Astronomy Research Seminar - The Impact on Students from their Perspective. Preliminary results from one spring seminar. -293}

the seminar dedicated to the writing process, generally $50 \%$ of the course. While some instructors express concern that students may not be happy with the course focusing more on writing than astronomy content, the survey results indicate that many students value the writing experience they gained in the seminar, with $91 \%$ of them not being discouraged by the amount of writing. It was surprising to see many students list the experience of writing a research paper as one of the biggest benefits of the seminar.

One of the fundamental reasons for offering the Astronomy Research Seminar is to give students the opportunity to experience as closely as possible the realities of doing scientific research as early in their educational career as possible. Most students don't conduct actual research until they are in graduate school, even if they are pursuing a STEM-related field. The thinking behind this seminar is that it could provide STEM-track students with earlier experience in conducting research and doing scientific writing, as well as help inspire students who might otherwise not do so to pursue STEM fields. The survey results indicate that at least for some students it really did inspire them to pursue or continue to do research.

Working in teams is an important aspect of science as well as a general 21 st century skill, and learning to manage their own teams is generally new to students. Most of them felt that they managed their own teams, and more than half felt that they at least had some choices within the scope of their project. Providing student choice in research will remain a challenge in a program done within the course of 8 weeks or even a semester, as options need to be constrained to ensure the project fits within the time frame given.

The astronomy research seminar really provides a unique experience for students, most of whom really value the many aspects that distinguish the course from traditional classes, including the management of their own teams, the rigorous introduction to the process of writing, and re-writing a scientific paper, and the opportunity to at least in some small degree choose their project.
The recent expansion of the seminar to new schools and new geographic regions will provide many more opportunities to examine the program and improve on it, was well as to evaluate it more thoroughly as to the short- and long-term impacts it may have on student educational and career choices.

\section{Conclusion and Future Directions}

A similar survey to the one used in the analysis presented above will continue to be used in the upcoming semesters to collect information on students' self-reported ideas about scientific research and writing and their abilities to participate in these endeavors. The seminar is expanding significantly and it may be instructive to compare future groups of students from diverse geographical regions, taking the course at different institutions with a variety of instructors and studying different aspects of astronomy.

Beginning in a few months there will also be a content knowledge evaluation component to this program whereby a pre- and post-test will be administered to students to look at gains in content knowledge about the astronomical phenomenon being researched by the students as well as their understanding of the research and scientific communication processes.

Additionally, the researchers are beginning an ex post facto analysis, reaching out to as many of the several hundred past seminar participants as they can locate to ask about similar reflections. They will also be doing interviews and focus groups to get more detail about both the potential short term and long term impacts that the seminar may or may not have had on students moving into stem fields in their education and career paths.

\section{References}

Clark, R. (2010). All About the Journal of Double Star Observations. In Genet, R., Johnson, J., and Wallen, V., editors, Small Telescopes \& Astronomical Research. Collins Education Foundation, Santa Margarita, California. 
Fitzgerald, M. T., Hollow, R., Rebull, L. M., Danaia, L., and McKinnon, D. H. (2014). A review of high school level astronomy student research projects over the last two decades. Publications of the Astronomical Society of Australia, 31.

Freed, R., Fitzgerald, M., Genet, R., and Davidson, B. (2017). An overview of ten years of student research and JDSO publications. In Society for Astronomical Sciences Annual Symposium, volume 36, pages 131-136.

Genet, R., Armstrong, J., Blanko, P., Boyce, G. B., Brewer, M., Buchheim, R., Calanog, J., Castaneda, D. C., Clark, R. K., Collins, D., et al. (2017). Student Scientific Research within Communities-of-Practice. In Society for Astronomical Sciences Annual Symposium, volume 36, pages 143-150.

Genet, R., Johnson, J., and Wallen, V. (2010). One-Semester Astronomical Research Seminars. In Genet, R., Johnson, J., and Wallen, V., editors, Small Telescopes \& Astronomical Research. Collins Education Foundation, Santa Margarita, California.

Genet, R. M. (2007). Developing an Undergraduate Astronomical Research Program. In Society for Astronomical Sciences Annual Symposium, volume 26, page 99.

Genet, R. M., Fulton, B., Bianco, F. B., Martinez, J., Baxter, J., Brewer, M., Carro, J., Collins, S., Estrada, C., Johnson, J., et al. (2012). Observing double stars. In Society for Astronomical Sciences Annual Symposium, volume 31, pages 147-157.

Gomez, E. L. and Fitzgerald, M. T. (2017). Robotic telescopes in education. Astronomical Review, 13(1):28-68.

Johnson, J. (2008). Double Star Research as a Forum of Education for Community College. In Society for Astronomical Sciences Annual Symposium, volume 27, page 25 .
Wenger, E. (1999). Communities of practice: Learning, meaning, and identity. Cambridge university press. 


\section{Appendix A Survey Questionnaire}

1. What level of school are you in?
a. High school
b. College
c. Other

2. What career do you hope to pursue after school? (i.e., engineer, lawyer, scientist, etc...)

3. How did the Astronomy Research Seminar most benefit you?

4. Did the seminar make you feel like you were doing real research, or did it seem mostly like an academic lab class as in chemistry, biology, or physics with known outcomes? Please explain.

5. Do you feel that your team went through (at least roughly) the same research process that professional research teams go through? Please explain briefly.

6. Did the seminar inspire you in any way? Please describe how.

7. When you realized how much careful writing scientists have to do, did this discourage you from thinking about becoming a scientist?

8. Did it work to have a team of student researchers or would it have worked better to do the research on your own?

9. Do you feel your team managed its own research, or did the research supervisor actually run the show for you?

10. Did you feel that you were able to make real choices, or was the path pretty well set in stone? Please briefly explain.

11. By the end of the seminar did you have at least a rough feel for what double star astronomy was about, or did it remain confusing to the very end?
12. Would you like to have spent more time making observations, or do you feel it was a good thing to make the observations as quickly as possible to leave time for analysis and, especially, paper writing.

13. With the advantage of hindsight, how important do you think it was that the seminar insisted on published results?

a. Without the publication requirement, the seminar would not have had much benefit to me.

b. The publication requirement took all the fun out of the seminar because we had to spend most of the time writing and rewriting our papers.

c. The publication requirement really sharpened our team's critical thinking.

$\mathrm{d}$. The publication requirement really made the seminar different than any course I had taken before then.

e. Other?

14. How helpful were the lecture videos in teaching you about astrometry?
a. Very helpful
b. Somewhat helpful
c. Not that helpful
d. I didn't watch the videos

15. How helpful were the lecture videos in teaching you how to write a research paper?
a. Very helpful
b. Somewhat helpful
c. Not that helpful
d. I didn't watch the videos

16. Did the quizzes match the objectives and reinforce the material you were learning in each unit? 

a. Yes.
b. Somewhat.
c. Not really
d. I don't know.

17. What was the most useful part of Canvas?

18. What could be improved in Canvas to make it more useful or clear?

19. Instead of research on double stars, would you rather have done research on: eclipsing binaries, intrinsically variable stars, exoplanet transits, asteroids, or the sun?

20. Did your team develop its own research ideas, or was there little or no choice?

21. Did writing a proposal help launch your project?

22. How difficult was it for your team to write up its paper? Very difficult, moderately difficult, easy.

23. How helpful was the external review in improving your team's paper?
a. A lot.
b. Not much.
c. Not at all.

24. Do you feel that your research contributed to the scientific community?
a. Yes.
b. Yes, but only in a very minor way.
c. No, it was, in the end, just
another academic exercise.

25. Do you feel that you were able to make a significant contribution to your team's research project?
a. Yes.
b. No.
c. Only marginally.

26. Did you have some unique talents that helped out your team? Explain.

27. Did your contribution to your team's research make you feel like you could contribute to teams in the future?

28. Do you think it really made any difference to you whether or not you received official college (or high school) credit for the seminar? Was the primary value doing actual research or having a published paper or something else? Please explain.

29. Did you think that being a coauthor of a published paper might help you obtain a scholarship?

30. Did you feel immersed within a supportive pro-am (professional-amateur) community or were you pretty much on your own?

31. Should the seminar have math or science prerequisites to make sure students were all able to contribute to the research, or did it work out to not have prerequisites and have team members relatively new to math and science?

32. Did your team members contribute equally to the team's project? Did this bother you that they didn't contribute equally? Did your team adjust author order in the final paper to take into account the degree of individual participation? Do you think what you came up with was fair?

33. Do you think the seminar did the right thing in allowing widely varying participation just like in real science research teams, or should the seminar work harder for equal student participation as is the case for most other classes?

34. Were there some students on your team that hardly participated at all? Was it fair to even include them as coauthors? What do you think we should have done with them? 
35. Were you given enough time to write the paper? We had enough time to write our paper. There wasn't enough time to do a good job in writing up our paper.

36. Do you think that, having participated in published research, you now have a better feel for what science is all about? Will this make you a better-informed citizen when it comes to moving our country forward in a positive manner? 